УДК 3977 JEL D24

Иванов Никита Андреевич

студент, ФГБОУ ВО «Московский государственный технический университет им. Н. Э. Баумана (национальный исследовательский университет)», г. Москва, Российская Федерация

ORCID: 0000-0002-2046-1897

e-mail: ivanov194947@gmail.ru, ivanovna2719@gmail.com

\section{Кашеварова Наталия}

Александровна

канд. экон. наук, ФГБОУ ВО «Московский государственный технический университет им. Н. Э. Баумана (национальный исследовательский университет)», г. Москва,

Российская Федерация

ORCID: 0000-0002-9842-7058

e-mail: n.kashevarova@bmstu.ru

\section{Nikita A. Ivanov}

Student, Bauman Moscow State Technical University, Moscow, Russia

ORCID: 0000-0002-2046-1897

e-mail: ivanov194947@gmail.ru, ivanovna2719@gmail.com

Natalia A. Kashevarova Cand. Sci. (Econ.), Bauman Moscow State Technical University,

Moscow, Russia

ORCID: 0000-0002-9842-7058

e-mail: n.kashevarova@bmstu.ru
DOI 10.26425/1816-4277-2021-7-43-51

\section{АНАЛИЗ ИСПОЛЬЗОВАНИЯ СИСТЕМЫ ЭЛЕКТРОННОГО ДОКУМЕНТООБОРОТА В ФЕДЕРАЛЬНЫХ ОРГАНАХ ИСПОЛНИТЕЛЬНОЙ ВЛАСТИ}

\begin{abstract}
Аннотация. Система электронного документооборота - один из самых популярных продуктов для внедрения на различных предприятиях в самых разных отраслях, начиная от тяжелой промышленности и заканчивая государственными организациями и федеральными органами власти. Документооборот во многих компаниях ведется на бумажных носителях, а это, в свою очередь, вызывает большие трудности при обработке, хранении и исполнении документов. Бумажные архивы занимают сотни квадратных метров складских помещений, и при необходимости нужный документ очень сложно найти среди большого количества макулатуры. В связи с этим многие компании начинают пересматривать свою деятельность и уходить от бумажного документооборота к электронному.
\end{abstract}

Ключевые слова: система электронного документооборота, внедрение, документооборот, бумажные архивы, документы, анализ, федеральные органы власти, государственные организации, деятельность компаний

Для цитирования: Иванов Н.А., Кашеварова Н.А. Анализ использования системы электронного документооборота в федеральных органах исполнительной власти//Вестник университета. 2021. № 7. C. $43-51$.

\section{ANALYSIS OF THE USE OF THE ELECTRONIC DOCUMENT MANAGEMENT SYSTEM IN FEDERAL EXECUTIVE AUTHORITIES}

\begin{abstract}
The electronic document management system is one of the most popular products for implementation at various enterprises in various industries, ranging from heavy industry to state organizations and federal authorities. Document flow in many companies is carried out on paper, and this, in turn, causes great difficulties in processing, storing and executing documents. Paper archives occupy hundreds of square meters of storage space, and if necessary, it is very difficult to find the right document among a large amount of waste paper. In this regard, many companies begin to review their activities and move away from paper document management to electronic
\end{abstract}

Keywords: electronic document management system, implementation, document management, paper archives, documents, analysis, federal authorities, state organizations, company activities

For citation: Ivanov N.A., Kashevarova N.A. (2021) Analysis of the use of the electronic document management system in federal executive authorities. Vestnik universiteta, no. 7, pp. 43-51. DOI: 10.26425/1816-4277-2021-7-43-51

\title{
Введение
}

На сегодняшний день многие компании и организации стараются как можно эффективнее использовать все ресурсы для ведения свей деятельности. На рынке предлагается значительное количество различных информационных систем на любой вкус и бюджет. Среди них можно выделить CRM (от англ. Customer Relationship Management - «управление отношениями с клиентами»), ERP (от англ. Enterprise Resource Planning - «планирование ресурсов предприятия»), систему электронного документооборота (далее - СЭД) и др. Кроме частного сектора современные информационные технологии стали внедряться и в государственный сектор. В 2017 г. Д. А. Медведевым было подписано распоряжение № 1632-р «Об утверждении программы «Цифровая экономика Российской Федерации» [2]. Данная программа рассчитана на срок с 2017 г. по 2030 г., ее цель - создать информационное общество в Российской Федерации, в которую входят также создание экосистемы цифровой экономики Российской Федерации.

(с) Иванов Н.А., Кашеварова Н.А., 2021.

Статья доступна по лицензии Creative Commons «Attribution» («Атрибуция») 4.0. всемирная (http://creativecommons.org/licenses/by/4.0/).

(C) Ivanov N.A., Kashevarova N.A., 2021.

This is an open access article under the CC BY 4.0 license (http://creativecommons.org/licenses/by/4.0/).

(c) (i) 
Помимо этого, все чаще встает вопрос о формировании цифрового правительства. Данная программа подразумевает удобное взаимодействие между государственными и муниципальными органами и населением. Цель заключается в том, чтобы наладить бесшовную связь между различными порталами, сделать удобные сервисы и увеличить скорость ответа при запросах той или иной информации. В рамках данного направления как раз формируется система электронного документооборота между государственными и муниципальными организациями.

\section{Преимущества от внедрения СЭД}

Можно заметить, что цифровая трансформация протекает во многих отраслях. СЭД внедряется во многие государственные учреждения, особенно при следовании государственной программы по созданию «электронного правительства». При внедрении системы в организации повышается уровень исполнительской дисциплины, так как СЭД позволяет:

- вести учет (регистрировать и однозначно идентифицировать документ);

- предоставлять доступ (параллельно выполнять операции, тем самым сокращая время движения документов и повышая оперативность их исполнения);

- хранить документы;

- принимать управленческие решения, основываясь на данных из отчетов;

- искать документы, основываясь на гибком поиске.

Цель СЭД заключается в упрощении работы с документами для каждого сотрудника организации. Например, без СЭД на поиск документов уходит большое количество времени, в то время как при наличии системы сотрудник сможет без труда найти нужный документ по заданным атрибутам. При традиционном подходе к документообороту, реализуемому на бумажном носителе, достичь такого не получится [7].

Еще одна задача СЭД - обеспечивать контроль над исполнением заданий и поручений. Любое должностное лицо в организации сможет без труда понять, на каком этапе находится его поручение.

Мировая практика, подкрепляемая рядом исследований, показывает, что принимая решение о внедрении СЭД организации, как правило, преследуют три цели: повысить свою эффективность, оптимизировать бизнес-процессы и обеспечить соответствие законодательным требованиям [12].

\section{Анализ системы электронного документооборота в государственных организациях}

В 2013 г. Министерство связи и массовых коммуникаций Российской Федерации провело исследование по количеству внедренных систем электронного документооборота в федеральные органы исполнительной власти. Согласно данному исследованию, в 2013 г. СЭД активно использовался только 14 из 79 ведомств. Только 17 ведомств имели подключение к системе, обеспечивающей межведомственный электронный документооборот [11]. С тех пор ситуация менялась в лучшую сторону, и в 2021 г. Аппарат Правительства Российской Федерации выпустил постановление, согласно которому все федеральные органы исполнительной власти должны быть подключены к межведомственному электронному документообороту новой версии 2.7.1.

На данный момент есть два варианта внедрения СЭД в орган власти: внедрение СЭД во все ведомство и подключение одной системы между различными органами власти. Разберем каждый из вариантов более подробно.

При первом варианте СЭД внедряется во все государственные учреждения: и в центральный аппарат, и в территориальные управления, расположенные в регионах Российской Федерации. Пример такого внедрения можно найти в Федеральной антимонопольной службе Российской Федерации.

При втором варианте к одной СЭД подключаются несколько государственных организаций. Например, в некоторых регионах к внедренной в областное правительство СЭД подключаются местные органы государственной власти, тем самым создавая возможность расписывать резолюции из одного ведомства в другое.

\section{Анализ внедрения СЭД в органах власти}

В основную деятельность многих государственных органов входит рассмотрение заявлений по Указу Президента Российской Федерации от 17.04.2017 № 171 «О мониторинге и анализе результатов рассмотрения обращений 
граждан и организаций» [1]. Традиционный бумажный документооборот в органах государственной власти протекает чрезвычайно долго и влечет значительные затраты ресурсов на функционирование почтовых служб и канцелярии. Заявитель оперативно не может узнать, на какой стадии находится его обращение.

До внедрения СЭД процесс был следующим: заявитель отправлял обращение в государственный орган на бумажном носителе или по электронной почте. Документ регистрировался на бумажном носителе и передавался для расписывания резолюций от руководителя до конечного исполнителя. Минусы у такого процесса были следующие:

- одновременно с оригиналом документа не могли работать больше одного сотрудника;

- оригинал документа мог быть испорчен или потерян;

- для хранения документов приходилось отводить специальные помещения.

При внедрении СЭД все эти проблемы очень легко решаются. Карточка документа с отсканированным файлом заводится в системе и попадает всем заинтересованным лицам. Таким образом, с документом одновременно могут работать несколько сотрудников, а освободившееся место можно использовать более рационально. СЭД позволяет повысить исполнительскую дисциплину при подготовке документов, принимать управленческие решения на основании данных и отчетов по документообороту, снизить число потерь и организовать прозрачные процессы, допускающие контроль на каждой стадии [4]. Важность задачи состоит в том, что без правильно налаженного процесса документооборота будет невозможно наладить остальные процессы по организации работы в рамках проекта «Цифровое правительство», так как не будет четко построенной системы по обмену документами [9].

\section{Специфика внедрения СЭД в органы власти}

Из всего вышеперечисленного можно сделать вывод, что система электронного документооборота нужна в органе власти для оптимизации работы. В 2017 г. была утверждена программа «Цифровая экономика Российской Федерации». Логично предположить, что с приходом такого проекта многие государственные органы начнут оптимизировать и цифровизировать свою работу.

В 2017 г. вышел Указ Президента Российской Федерации № 171 «О мониторинге и анализе результатов рассмотрения граждан и организаций», согласно которому государственные органы и организации должны предоставлять отчет о работе по рассмотрению обращений граждан по Федеральному закону от 02.05.2006 № 59-Ф3 «О порядке рассмотрения обращений граждан Российской Федерации» [3]. Со временем появился портал ССТУ.РФ, куда государственные органы стали выгружать отчеты по работе с обращениями граждан. Соответственно, СЭД должна иметь функции:

- регистрации и обработки всех обращений согласно Указу Президента Российской Федерации от 17.04.2017 № 171 «О мониторинге и анализе результатов рассмотрения граждан и организаций»;

- контроля рассмотрения обращений, их сроков и фиксирование результатов;

- интеграции с порталом ССТУ.РФ для передачи информации о рассмотрении обращения [5].

Для обмена документацией существует специальный межведомственный электронный документооборот (далее - МЭДО). К данной системе подключены органы власти и государственные организации. Данная система нужна для безопасного обмена информации. Соответственно, СЭД должна иметь возможность:

- загрузки, регистрации и обработки документов, поступивших по МЭДО;

- отправки документов по МЭДО;

- хранения истории взаимодействия с МЭДО.

Среди всего прочего, СЭД должна обладать возможностью взаимодействия с Единым порталом государственных и муниципальных услуг (ЕПГУ) и Системой межведомственного электронного взаимодействия (СМЭВ).

\section{Методология проведения статистического анализа патентных данных}

Для того чтобы понять, в каком направлении будет идти развитие системы электронного документооборота, был проведен анализ патентных данных за период с 2015 г. по 2019 г. Для проведения статистического анализа патентных данных целесообразно пользоваться двумя поисковыми системами по патентам: Яндекс.Патент и Google Patents. 
Поисковая система Яндекс.Патент использовалась для анализа тенденции на российском рынке, ключевые слова были следующими: «СЭД», «система электронного документооборота», «электронный документооборот» и «документооборот». Для актуальности информации был выбран период с 2015 г. по 2019 г.

В результате было получено 128 патентов и заявок по рассматриваемой тематике. Поисковый запрос в международной базе патентной информации показал статистические данные о компаниях, участвующих в патентовании, ключевых направлениях международной патентной классификации (далее - МПК) и технологических методах, запатентованных каждой компанией.

По данному запросу была проанализирована динамика выдачи патентов и патентных заявок за последние 5 лет (рис. 1). Пик по количеству патентов был в 2017 г.: СЭД было выдано 33 патента. Наименьшее количество патентов было выдано в 2019 г. - 11 документов. Это можно объяснить тем, что с течением времени гораздо сложнее придумывать новые технологии, не запатентованные ранее. В связи с тем, что СЭД появилась на российском рынке относительно недавно, многие разработчики и компании стали изобретать и патентовать свои идеи касательно данной системы.

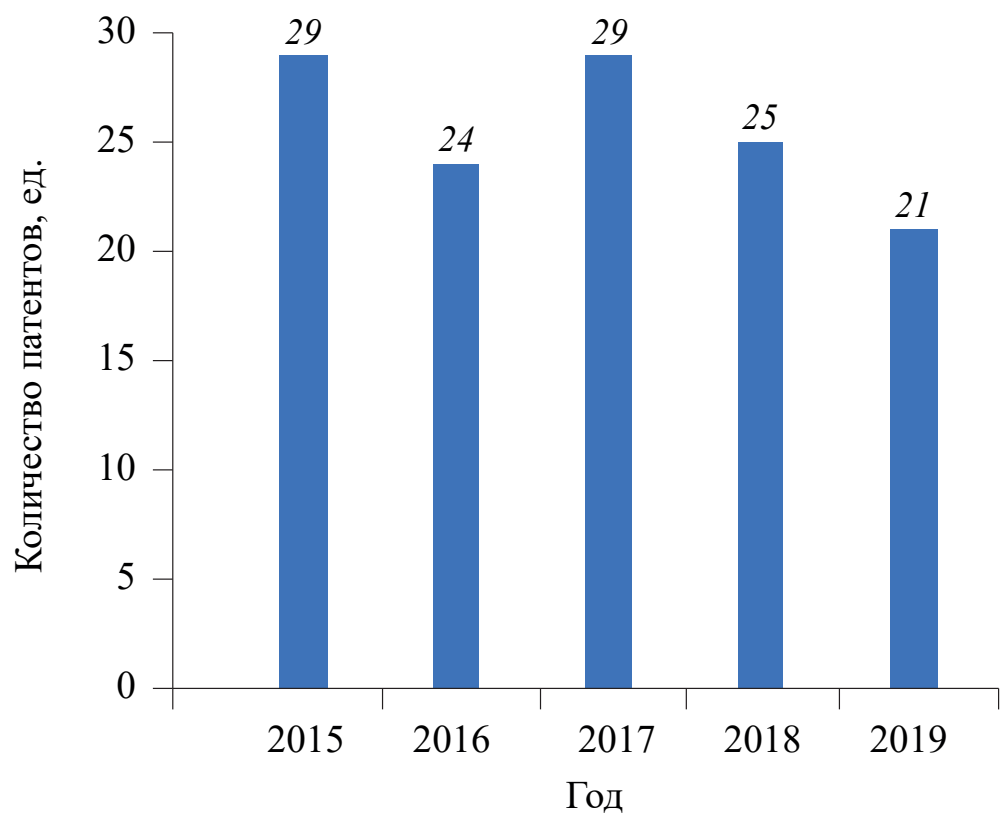

Составлено авторами по материалам исследования

Рис. 1. Количество патентов по СЭД по годам

Далее был сформирован второй запрос в патентной поисковой системе Google Patents по определенным ранее подклассам МПК, запрос составлен по ключевым словам и рассматривался в период 2015-2019 гг. На основе полученных данных были выделены страны-лидеры по патентованию за 10 лет, была проанализирована динамика выдачи патентов по 4 наиболее значимым подклассам за последние 10 лет в России и в ведущих странах мира. Далее построены графики, отражающие патентную активность компаний-лидеров отрасли в России и за рубежом за последние 10 лет.

В качестве последующего шага исследовательской работы был произведен анализ патентных портфелей выявленных компаний-лидеров, а также определены наиболее востребованные технологии искусственного интеллекта для патентной аналитики на основе исторических данных.

\section{Анализ исследования крупных патентообладателей}

Для понятия развития технологии СЭД и выявления патентных тенденций в этой области был сформирован запрос в патентных поисковых системах Яндекс.Патент и Google Patents на выдачу патентов за последние 5 лет. На рисунке 2 наглядно показаны произошедшие изменения. 


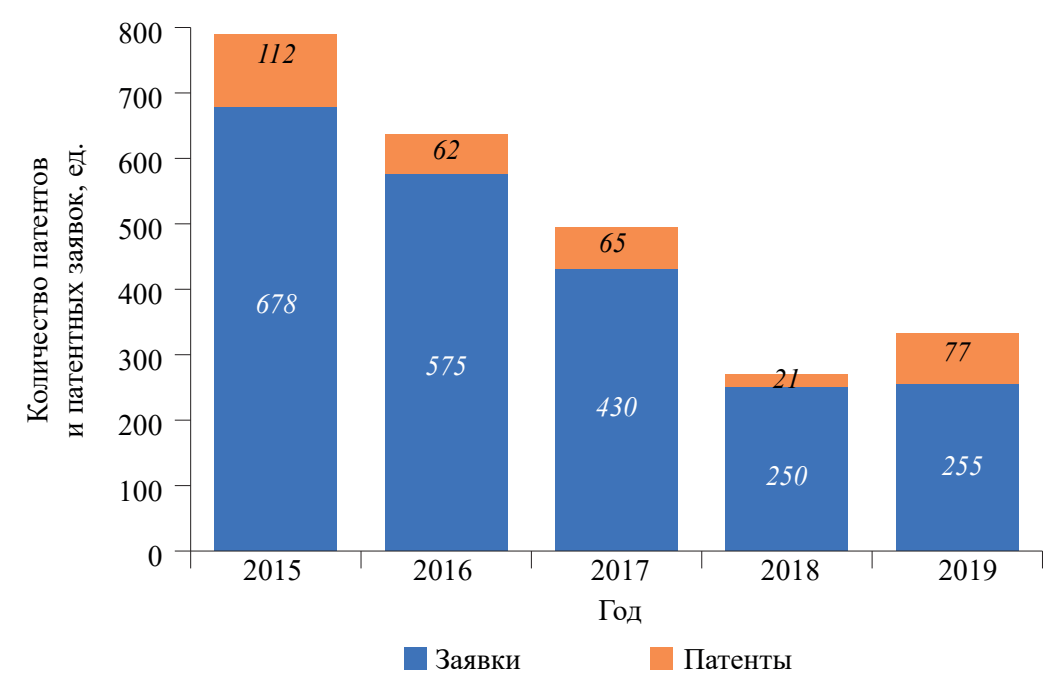

Составлено авторами по материалам исследования

Рис. 2. Распределение выданных в 2015-2019 гг. патентов и патентных заявок в мире

Из рисунка 2 видно, что число патентов составляет лишь малую долю от общего числа поданных заявок. Это говорит о трудности выполнения условий для приобретения патента. Также отмечается тенденция к увеличению количества патентных заявок за последние годы, хотя и наблюдается снижение заявок в 2019 г. Такая положительная тенденция свидетельствует о растущем интересе к области применения новейших технологий для целей патентного анализа.

Во время исследования было выявлено несколько компаний, которые чаще остальных подавали патентные заявки на технологии в области EDMS (системы управления документами). Рассмотрим две организации, которые имеют максимальное число патентов и патентных заявок в области системы управления документами.

Одна из крупнейших в мире компаний, специализирующихся на защите данных - Commvault Systems, поэтому не удивителен тот факт, что большинство патентов разработано как раз в области управления базами данных, резервных копирований и защиты информации. В последнее время на рынке информационных технологий мы можем наблюдать тренд по переводу всевозможных данных в облачную систему. Commvault Systems изобретает различные системы для плавного и безопасного перехода в облачную систему производителей и поставщиков аппаратного и программного обеспечения, а также сервисов информационных технологий и консалтинговых услуг (рис. 3).

Системы управления базами данных

Системы резервного копирования

Облачные файловые системы

Операции защиты данных

Мобильные приложения (версии) СЭД

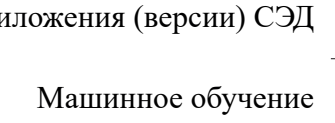

Управление контентом

$$
+
$$

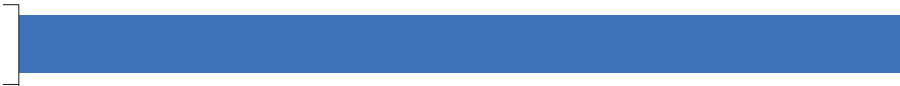

111

Составлено авторами по материалам исследования

Рис. 3. Статистика по Commvault Systems 
Также как и Commvault Systems, компания Pearson Education занимается разработкой в области систем управления базами данных и систем резервного копирования (рис. 4). Данная компания занимается предоставлением контента, оценки и цифровых услуг учащимся, учебным заведениям, работодателям, правительствам и другим партнерам по всему миру. В компании работает свыше 22000 сотрудников в различных странах, поэтому она стремится соответствовать всем требованиям современного мира, чтобы предлагать своим клиентам наиболее качественные и безопасные услуги. Мы также можем наблюдать, что у компании присутствуют патенты в области разработок для мобильных версий и машинного обучения. Среди таких патентов можно выделить разработку мобильных приложения для взаимодействия документов и различных участников платформы компании, которая позволяет быстро находить и использовать всю информацию, а также обмениваться ей.

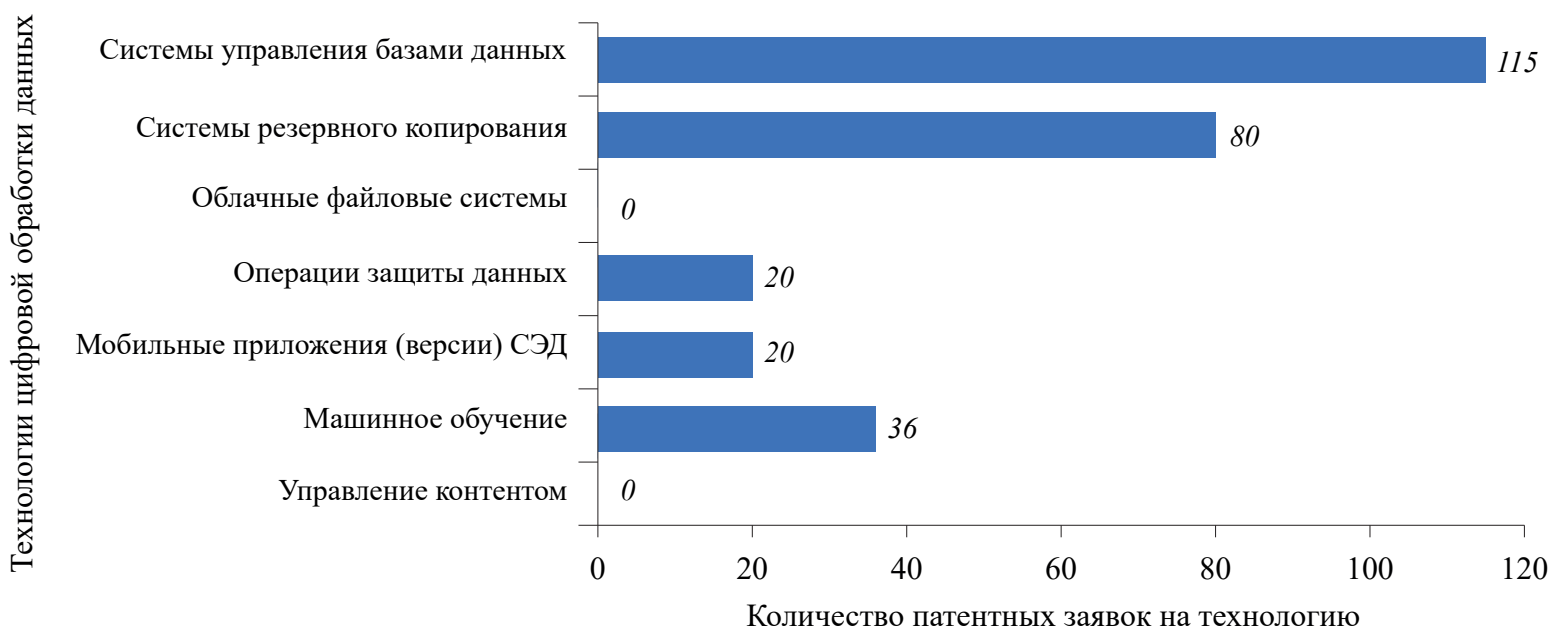

Составлено авторами по материалам исследования

Рис. 4. Статистика по Pearson Education

С точки зрения пользовательского опыта, в классическую СЭД добавить практически нечего. Поэтому, как мы видим из анализа исследования выше, основными патентами в области СЭД становятся внутренние системы для более комфортной и безопасной работы. Многим организациям от СЭД нужна только возможность ведения документооборота, так как все остальные системы уже имеются, поэтому появляется требование в правильной интеграции всех систем. Часто бывает, что данные требования становятся ключевым фактором при выборе той или иной системы.

\section{Тенденции развития системы электронного документооборота}

B 2020 г. пандемия COVID-19 стала одной из главных причин для внедрения СЭД. В связи со всеобщей изоляцией стало невозможно вести документы на бумажном носителе. Рост рынка СЭД за 2020 г. по предварительным оценкам составил порядка 9\%, что на 1-2 \% больше показателей 2019 г. На рисунке 5 представлен график развития СЭД на российском рынке. Стоит отметить и тот факт, что за последние несколько лет повысился спрос на отечественные системы, так как они ничуть не уступают западным, а стоят дешевле [10].

Самыми востребованными пользовательскими функциями являются возможность использования электронной подписи, автоматическое распознавание текстов документов, создание приложений под мобильные устройства на базе IOS и Android, возможность подключения в закрытую корпоративную сеть из любой точки мира, формирование различных отчетов для принятия решений, использование штрих-кодов и QR-кодов. На сегодняшний день системы электронного документооборота имеют практически одинаковый набор функций, поэтому большое количество разработок ведется в части безопасности системы. Главным требованием во многих государственных организациях - это полный переход на отечественное программное обеспечение. Формально для соответствия политике импортозамещения продукт должен быть создан отечественным производителем, быть в реестре Министерства цифрового развития, связи и массовых коммуникаций Российской Федерации и поддерживаться СПО. Многие системы подходят под эти 
требования, и у большинства систем есть как десктопные (от англ. desktop - рабочий стол компьютера), так и веб-клиенты. Однако веб-клиент, как правило, уступает по своей функциональности десктопному, который работает в полную силу только на Windows. Также многие СЭД были разработаны под использование Microsoft Office, и теперь в срочном порядке требуется переходить на отечественные аналоги [14].

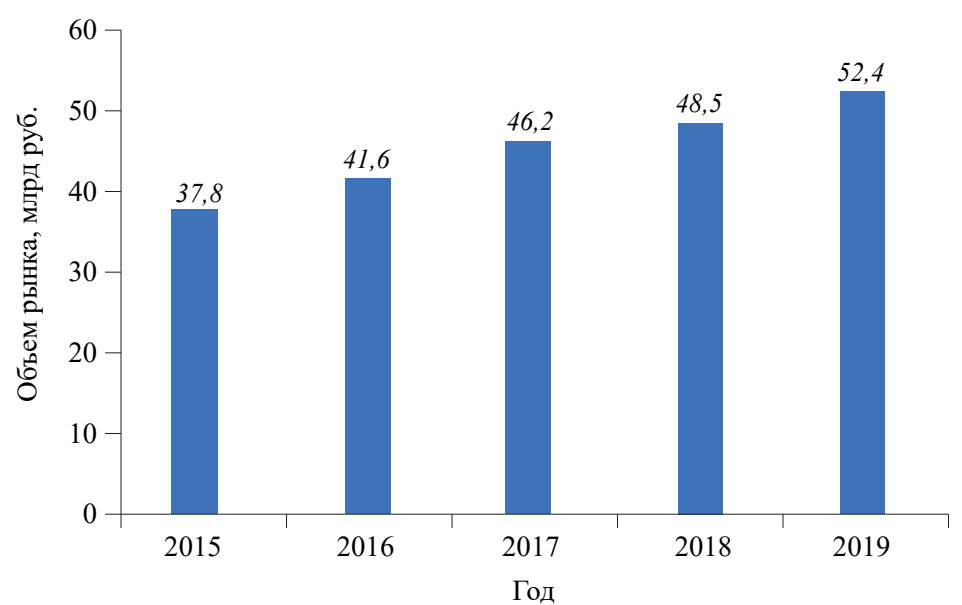

Составлено авторами по материалам исследования

Рис. 5. Объем российского рынка СЭД

Если говорить о глобальной тенденции развития СЭД, то банковский сектор предъявляет все больше новых требований при внедрении и обеспечении уже имеющихся систем. Это говорит о том, что организации стремятся сделать свои продукты наиболее удобными и безопасными в работе [13].

Среди популярных нововведений совершенствуется не столько пользовательский интерфейс, сколько технические нововведения, которые простой пользователь вряд ли заметит. Данные новшества служат для обеспечения более стабильной и безопасной работы системы [6]. Среди таких тенденций стоит выделить:

- управление базами данных;

- совершенствование систем резервного копирования;

- совершенствование безопасности системы.

\section{Вывод}

Таким образом, можно сделать вывод, что СЭД является популярной системой для внедрения в различные организации. Кроме того, специфика внедрения СЭД в государственный орган отличается от внедрения в любую коммерческую организацию прежде всего повышенными требованиями к безопасности и возможностью интегрирования с различными системами [8]. При внедрении необходимо провести анализ бизнеспроцессов, разобраться с маршрутами входящих, исходящих и внутренних документов. Государственный орган не может существовать самостоятельно, он всегда контактирует с гражданами и другими организациями, поэтому необходимо предусмотреть возможность интеграции внедряемой СЭД с различными продуктами, а также сделать открытым API (от англ. Application Programming Interface - «программный интерфейс приложения»). После проведенного анализа необходимо разработать регламент процессов, провести обучение, настроить все рабочие места и обеспечить возможность обращения в техническую поддержку. Только предусмотрев все эти меры, можно сказать, что внедрение получится и продукт будет пользоваться спросом.

\section{Библиографический список}

1. Указ Президента Российской Федерации от 17.04.2017 № 171 «О мониторинге и анализе результатов рассмотрения граждан и организаций» // Официальный сайт Президента Российской Федерации [Электронный ресурс]. - Режим доступа: http://www.kremlin.ru/acts/bank/41869 (дата обращения: 05.03.2021).

2. Распоряжение Правительства Российской Федерации от 28.07.2017 № 1632-р «Об утверждении программы «Цифровая экономика Российской Федерации» // Официальный сайт Правительства Российской Федерации [Электронный ресурс]. Режим доступа: http://government.ru/docs/28653/ (дата обращения: 05.03.2021). 
3. Федеральный закон от 02.05.2006 № 59-Ф3 «О порядке рассмотрения обращений граждан Российской Федерации» // СПС «КонсультантПлюс» [Электронный ресурс]. - Режим доступа: http://www.consultant.ru/document/cons_doc_LAW_59999/ (дата обращения: 05.03.2021).

4. Белов, С. П. Подготовка предприятий к внедрению систем электронного документооборота: монография. - М.: Мир науки, 2016. -210 с.

5. Жильников, А. Ю., Михайлова, О. С. Электронный документооборот // Территория науки. - 2017. - № 2. - С. $116-120$.

6. Калач, А. В., Зыбин, Д. Г. Организация систем электронного документооборота: монография. - Воронеж: Научная книга, 2020. $-158 \mathrm{c}$.

7. Медведева, О. В., Парамонова, М. Г. Цифровизация управления и системы электронного документооборота // Ученые записки Тамбовского отделения РоСМУ. - 2019. - № 13. - 75-80.

8. Романченко, Е. В. Теоретические и практические аспекты внедрения систем электронного документооборота в холдингах Российской Федерации: автореф. дисс. ... канд. ист. наук: 05.25.02 // Всероссийский научно-исследовательский институт документоведения и архивного дела. - М., 2013. -27 с.

9. Золотова Т. Бумажная беда цифровой трансформации // Ведомости [Электронный ресурс]. - Режим доступа: https://www. vedomosti.ru/opinion/articles/2018/10/29/785065-tsifrovoi-transformatsii (дата обращения: 05.03.2021).

10. Итоги рынка системы электронного документооборота в 2020 году и актуальные тенденции года // Софтэксперт [Электронный ресурс]. - Режим доступа: https://www.sfx-tula.ru/news/infoblog/10353/ (дата обращения: 05.03.2021).

11. Сведения о результатах исследования внедрения систем электронного документооборота в федеральных органах исполнительной власти // Официальный сайт Министерства цифрового развития, связи и массовых коммуникаций Российской Федерации [Электронный ресурс]. - Режим доступа: https://digital.gov.ru/ru/documents/3837/ (дата обращения: 05.03.2021).

12. СЭД (Рынок России) // TAdviser [Электронный ресурс]. - Режим доступа: https://www.tadviser.ru/a/53815 (дата обращения: 05.03.2021).

13. Функции и задачи ЭДО // Официальный сайт АО «Калуга Астрал» [Электронный ресурс]. - Режим доступа: https://astral. ru/business/elektronnyy-dokumentooborot/funktsii-i-zadachi-edo/ (дата обращения: 05.03.2021).

14. Docsvision (СЭД/ЕСМ - система) // TAdviser [Электронный ресурс]. - Режим доступа: https://www.tadviser.ru/a/153678 (дата обращения: 05.03.2021).

\section{References}

1. Decree of the President of the Russian Federation No. 171 dated April 17, 2017 "On Monitoring and Analysis of the Results of Consideration of Citizens and Organizations", Official website of the President of the Russian Federation. Available at: http://www.kremlin.ru/acts/bank/41869 (accessed 05.03.2021).

2. Order of the Government of the Russian Federation dated July 28, 2017 "On Approval of the Program "Digital Economy of the Russian Federation", Official website of the Government of the Russian Federation. Available at: http://government.ru/docs/28653/ (accessed 05.03.2021).

3. Federal Law No. 59-FZ dated May 2, 2006 "On the Procedure for Considering Appeals of Citizens of the Russian Federation", Legal reference system "ConsultantPlus". Available at: http://www.consultant.ru/document/cons_doc_LAW_59999/(accessed 05.03.2021).

4. Belov S. P. Preparation of the enterprise for the introduction of electronic document management systems: monograph, Moscow, Mir nauki, 2016, $210 \mathrm{p}$.

5. Zhilnikov A. Yu., Mikhailova O. S. Electronic document management, Territoriya nauki, 2017, no 2, pp. 116-120.

6. Kalach A. V., Zybin D. G. Organization of electronic document management systems: monograph, Voronezh, Nauchnaya kniga, 2020,158 p.

7. Medvedeva O. V., Paramonova M. G. Digitalization of management and electronic document management systems, Scientific notes of the Tambov branch of the RUYS, 2019, no 13, pp. 75-80.

8. Romanchenko E. V. Theoretical and practical aspects of the introduction of electronic document management systems in the holdings of the Russian Federation: Author's abstract diss. ... Cand. Sci. (Hist.): 05.25.02, All-Russian Research Institute for Records and Archives Management, Moscow, 2013, 27 p.

9. Zolotova T. Paper trouble of digital transformation, Vedomosti. Available at: https://www.vedomosti.ru/opinion/articles/2018/10/29/785065-tsifrovoi-transformatsii (accessed 05.03.2021).

10. Results of the market of the electronic document management system in 2020 and current trends of the year, Softekspert. Available at: https://www.sfx-tula.ru/news/infoblog/10353/ (accessed 05.03.2021). 
11. Information about the results of the study of the introduction of SED in the federal executive authorities, Official website of the Ministry of Digital development, Communications and Mass Media of the Russian Federation. Available at: https://digital.gov. $\mathrm{ru} / \mathrm{ru} /$ documents/3837/ (accessed 05.03.2021).

12. EDMS (Russian Market), TAdviser. Available at: https://www.tadviser.ru/a/53815 (accessed 05.03.2021).

13. Functions and tasks of electronic document management, Official website of the Joint-Stock Company "Kaluga Astral”. Available at: https://astral.ru/business/elektronnyy-dokumentooborot/funktsii-i-zadachi-edo/ (accessed 05.03.2021).

14. Docsvision (EDMS/ECM system), TAdviser. Available at: https://www.tadviser.ru/a/153678 (accessed 05.03.2021). 